\title{
Agôn
}

Revue des arts de la scène

Critiques | Saison 2010-2011

\section{De la joute à la jubilation critique}

Instants critiques, mise en scène François Morel

\section{Marie Duret-Pujol}

\section{(2) OpenEdition}

Journals

Édition électronique

URL : http://journals.openedition.org/agon/1689

DOI : 10.4000/agon.1689

ISSN : 1961-8581

Éditeur

Association Agôn

Référence électronique

Marie Duret-Pujol, « De la joute à la jubilation critique », Agôn [En ligne], Critiques, mis en ligne le 27 mai 2011, consulté le 23 septembre 2020. URL : http://journals.openedition.org/agon/1689 ; DOI : https:// doi.org/10.4000/agon.1689

Ce document a été généré automatiquement le 23 septembre 2020

Association Agôn et les auteurs des articles 


\section{De la joute à la jubilation critique}

Instants critiques, mise en scène François Morel

\section{Marie Duret-Pujol}

Après Les Habits du dimanche (créé en 2001), Collection particulière ou encore Bien des choses (tous deux créés en 2006), François Morel propose son dernier spectacle, Instants critiques, un montage de débats tenus entre Jean-Louis Bory et Georges Charensol dans les années 1960-1970 dans l'émission radiophonique Le Masque et la Plume avec, sur le plateau, les comédiens Olivier Saladin et Olivier Broche ainsi que la chanteuse et pianiste Lucrèce Sassella. Malgré la hauteur de la gageure, François Morel parvient à transformer le débat critique en objet de spectacle, dont le sujet dépasse le cadre du théâtre.

Instants critiques, mise en scène de François Morel

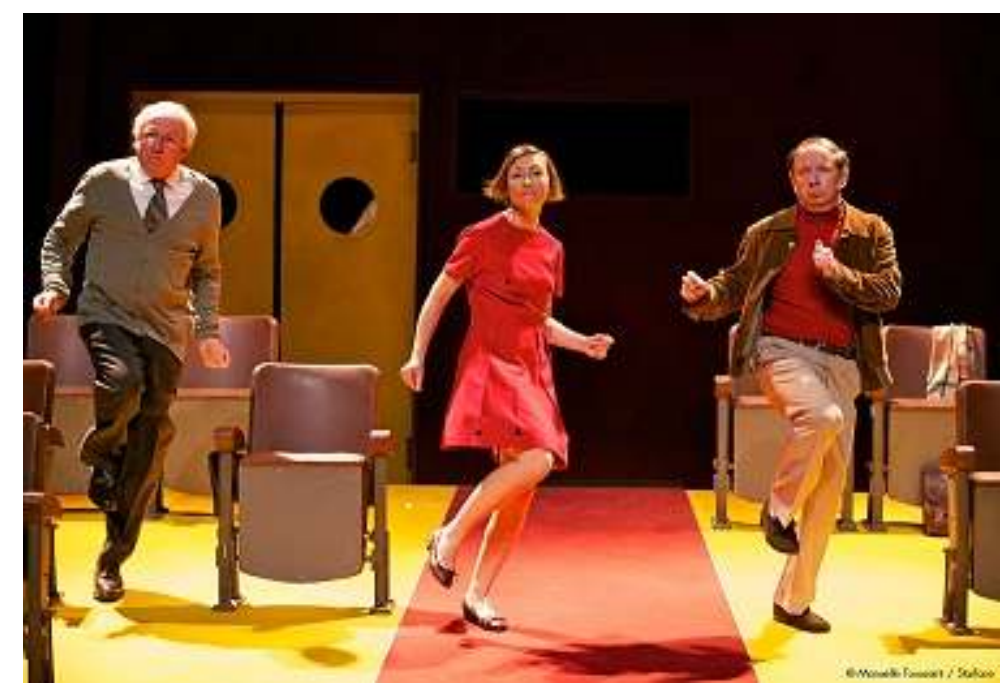

(C) DR 


\section{Un vrai spectacle sur la critique}

2 Avec une heure quarante de débats portant sur des films qu'une partie du public n'aura pas toujours vus, le tout dans un discours argumenté et soutenu, le pari comportait des risques. Le titre l'annonce : Instants critiques propose de réactiver des échanges critiques, douze au total. Si ces échanges sont datés, ils font surtout date, portant la ferveur des débats intellectuels des années 1960 et de l'après 68. Le choix des textes permet en effet d'assister à de truculentes joutes verbales qui présentent toute la palette oratoire offerte par la rhétorique critique. Les argumentaires sont solides, cherchant sinon à convaincre du moins à faire entendre un jugement critique, les arguments valorisants introduisent les discours pour mieux descendre les films par la suite, les attaques acerbes laissent la place à l'esquive (ainsi quand Bory s'échappe par un : « je ne préfère pas en parler » à propos d'Une belle fille comme moi de Truffaut). Les formules et les phrases qui font mouche foisonnent (« c'est intéressant ce débordement de yaourt ", s'autorise à dire Bory à propos des films pornographiques). Les deux hommes jouent sur les mots et cherchent les plus à même de traduire leur pensée, pinaillant sur les adjectifs " vulgaire » et " canaille ", débattant des limites entre " pornographie » et " érotisme ». Entre accords et désaccords, ententes et mésententes, la courtoisie polie laisse la place au franc énervement et à la mauvaise foi, donnant lieu à des rixes magnifiques.

3 À partir de cette judicieuse sélection d'extraits, François Morel parvient à contourner les difficultés et les pièges du montage à travers une dramaturgie pertinente et inventive. Il insère dans les dialogues des saynètes chantées et dansées qui ne viennent pas illustrer le propos mais le complètent et qui ménagent un rythme propice au maintien continu du spectateur en haleine. Le tout est soutenu par un comique riche, lié au jeu des comédiens et aux trouvailles de mise en scène. Pour ne citer que quelques exemples, Olivier Broche adopte un ton professoral pour le discours de Bory sur Le Corniaud de Gérard Oury, qu'il complète à l'aide d'un tableau et d'une baguette ; à propos de Mort d'un pourri de Georges Lautner, Olivier Saladin (Charensol) illustre les propos de son collègue par une imitation hilarante d'Alain Delon, tous deux rejouent en playback une scène des Parapluies de Cherbourg. Olivier Broche et Olivier Saladin, qui sont avant tout des comédiens de plateau, n'hésitent pas à investir les espaces entre les répliques pour créer des jeux de scène jouissifs.

4 Ils jouent ainsi avec l'image étriquée du critique assassin et désacralisent le mythe, en égratignant l'aura qui entoure encore, malgré tout, la profession (le critique journalistique reste perçu comme celui qui détient un certain savoir qui lui permet d'aiguiller le spectateur dans ses choix de spectacles). Le tableau est complété par leur relation avec la chanteuse qui, en leur proposant de courtes chorégraphies et des chansons issues de la bande originale des films (La ligne de chance, Une belle fille comme moi), donne à voir des hommes ne se réduisant pas à leur seul intellect. Cette chanteuse à la voix cristalline, première destinatrice et spectatrice des débats brise elle aussi les préjugés quant à l'aigreur des critiques qui seraient tous, on le sait bien, « des artistes ratés ", et les amène à dévoiler leur sensibilité. La succession des débats croisés par ces scènes apporte une autre teneur au spectacle tout en en soutenant la densité ; car, si les luttes entre les deux critiques sont ardues, elles laissent percevoir ce qui réunit les deux hommes, en dépit de leurs divergences esthétiques : leur passion pour le cinéma. 


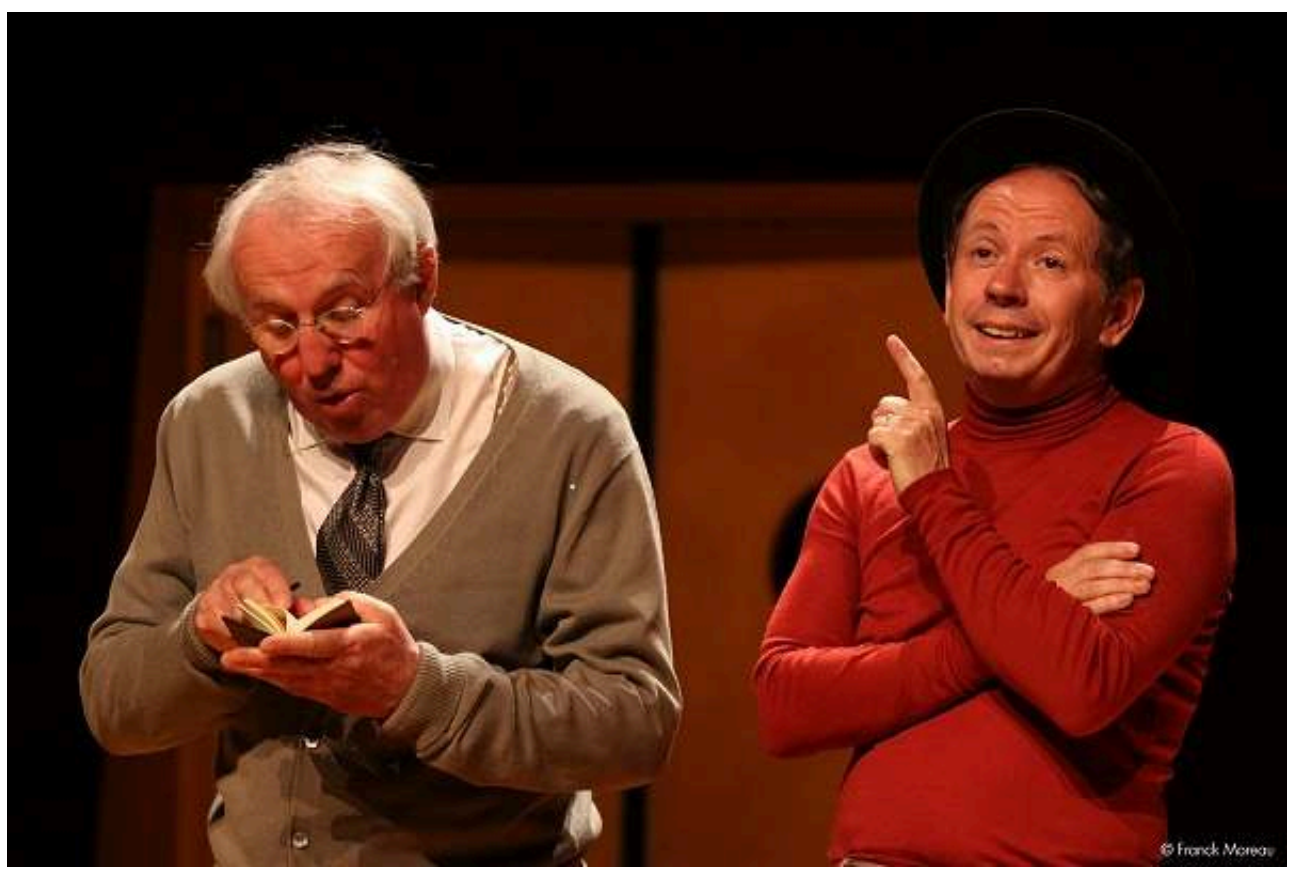

(c) DR

\section{Un spectacle vrai sur la critique}

Le discours s'adresse à un public de théâtre a priori coutumier de ce type de discussions et, même si tous n'écoutent pas d'émissions critiques telles Le Masque et la Plume ou Esprit Critique, on peut toutefois supposer qu'au sortir du spectacle, ils expriment leur avis et leur ressenti de spectateur, du moins dans un cercle privé. On pourrait donc objecter que de porter au plateau des débats critiques sur une scène nationale serait, somme toute, un acte consensuel, puisqu'il s'agirait d'un spectacle de théâtre fait pour des spectateurs de théâtre, soit un spectacle de nature à les conforter dans leur savoir (ils possèdent les références culturelles) et leur jugement (ils ont eux aussi aptes à étayer un point de vue sur un objet artistique).

6 Il serait pourtant bien réducteur de soupçonner Instants critiques d'être un « spectacle de communication ${ }^{1}$, tel que l'entend le sociologue Christian Malaurie, c'est-à-dire un spectacle qui offre au spectateur ce qu'il attend. Les ambiances sont ainsi seulement esquissées (une cigarette, une pipe allumées et quelques fumigènes ramènent à l'époque où il était encore permis de fumer dans les salles de cinéma) et les clins d'œil aux films juste amorcés. Sans cliché ni tape-à-l'œil, la mise en scène avisée de François Morel, qui fait la part belle au jeu du comédien, permet au texte d'advenir sans démagogie ni didactisme, et l'attaque d'un spectacle consensuel devient inopportune.

7 En évitant ces deux travers, qui auraient rendu le tout convenu, les problématiques évoquées émergent de manière subtile. Le spectacle aborde ainsi la question du jugement esthétique, en lien avec celle du beau et du goût, notamment à propos des films commerciaux ou des films comiques. Il est également question de la légitimité du - et de la - critique lorsque la chanteuse Lucrèce Sassella se fait la voix des auditeurs et intervient dans les débats, rappelant les deux hommes à l'ordre. La marge entre 
l'objectivité et la subjectivité que requiert l'exercice, et la fermeture de certains débats, par défaut de la prise en compte des destinataires de la critique, sont encore sensibles dans les excès de mauvaise foi (Charensol : « Au fond tu ne t'intéresses qu'aux riches ! $»)$.

8 La persistance de ces problématiques non encore résolues (d'ailleurs, faut-il qu'elles le soient ?), abordées par le biais du cinéma sur un plateau de théâtre, ouvre le spectacle sur l'état général de la critique aujourd'hui. Jean-Louis Bory et Georges Charensol, qui ont officié derrière les micros du Masque et la Plume durant plusieurs saisons, étaient deux ardents défenseurs de leurs idées et de la critique, qui osaient aller au bout de leur pensée, quitte à s'affronter de manière virulente. Et, s'il n'est pas nécessaire de défendre le bien-fondé de la critique qui permet de discerner, distinguer et discriminer au sein d'une production artistique abondante, luttant contre une certaine tendance à l'harmonisation (voire à l'uniformisation), on peut toutefois s'interroger sur son état aujourd'hui. À l'heure de la prolifération des blogs et des sites internet, qui mettent sur un même plan la critique, les avis de spectateurs et les billets d'humeur, alors que s'amenuise la place qui lui est réservée dans les médias, la question posée par la revue Mouvement en 2008, " la critique est-elle morte ? ${ }^{2}$ mérite, derrière ses airs provocateurs, d'être débattue. En choisissant de porter ces débats au plateau, Instants critiques encourage ces interrogations en filigrane.

Refusant la séduction (au sens premier de " détournement ») et sans être séducteur, le spectacle en devient séduisant, c'est-à-dire convaincant. François Morel propose ainsi un spectacle juste, qui n'est pas le « spectacle de plus ». Et alors qu'il n'avait plus à rien à prouver en tant que comédien et après s'être essayé à la chanson, François Morel passe haut la main le cap de la mise en scène.

Création en mai 2011, La Coursive, La Rochelle. Tournée au Théâtre des Célestins, Lyon du 31 mai au 10 Juin.

\section{NOTES}

1. Christian Malaurie, Le spectacle de l'ordinaire, essai inédit.

2. «La critique est-elle morte ? ", dossier coordonné par Gwénola David et Tiago Bartolomeu Costa, Mouvement, l'interdisciplinaire des arts vivants, $n^{\circ} 49$, octobre-décembre 2008, pp.48-53.

\section{INDEX}

Mots-clés : Instants critiques, Morel (François) 